\section{ON LOCAL WIRELESS REMOTE CONTROL}

ALENA GALAJDOVA, ROBERT RAKAY

Faculty of Mechanical Engineering, Department of Automation and Human Machine Interactions, Kosice, Slovakia

DOI: 10.17973/MMSJ.2020_11_2020034 alena.galajdova@tuke.sk

The article deals with the design of a home automation system. The proposed system combines wireless data transmission and positioning device. The main components and their parameters, which are necessary for building such system and base steps how to create and test a device are described. The created system can serve as a suitable basis for a truly deployed system with minor changes, as the tested drive has not been connected to any moving object, it can also serve as an example in the education of students in fields such as Automation or Mechatronics.

\section{KEYWORDS}

Remote control, wireless communication, micro system, microcontroller.

\section{INTRODUCTION}

The goal to create remote control systems is to operate other devices from a distance. First systems were realized by connecting the operator and the actuator trough wires on shortrange teleoperation systems. At present this kind of solutions are applied only for dangerous tasks implemented in radioactive or explosive environments, where the operator could be endangered. Nowadays the wireless data transfer replaced the wired connection and the solutions are aimed to make everyday life easier and more comfortable for every person in society [Galajdová 2009, Krenicky 2011, Šeminský 2015]. Wireless remote control systems help with tasks such as control of lights or heating, ventilation, and air conditioning (HVAC), opening and closing of doors, windows and controlling of different electrical devices [Šimšík 2016, Ketshabetswe 2019].

Nevertheless, every manufacturer of the modern home automation system uses an Internet connection, not every task requires it. People with temporary or permanent disabilities can use local wirelessly controlled appliances, where the remote control system can be built using wireless communication protocols as:

Bluetooth, BLE, ESPNow, LoRA, and other RF-based protocols. Each of these communication tools shares from low to medium range, lower transfer rates and connection limitations. Despite the limitations of the above-mentioned protocols, they can be integrated to control lights, blinds, and other simple devices. The transferred data doesn't contain any private information and in the most cases, they are not time-critical too [Kar 2017].

By integrating electrical actuators, we can carry out different functions. For example, a servo motor can replace the activity such as a door or hatch opening and closing.

The minimal requirement to determine the applicability of the servo motor is to specify the torque. The torque is a force applied at a right angle to a lever multiplied by its distance from the lever's fulcrum (the length of the lever arm).

For a theoretical lift of a $2 \mathrm{~kg}$ object and the lever arm of $2 \mathrm{~cm}$ length, we need at least $0.4 \mathrm{Nm}$ torque.

For the purpose of an experimental system testing, there is no exact activity to be controlled remotely, and the devices are tested only as a laboratory model. The main goal is to control the position of the servomotor.

The proposed system consists of a transmitter device and receiver device, which are networked via the nRF24 modules (Fig. 1). The input of the system is an analog signal which is transferred to the microcontroller. This voltage value is read and processed to a digital value by within the Arduino. The processed value is then sent to the receiver of the system. The received message is processed and is used for attached servomotor controlling.

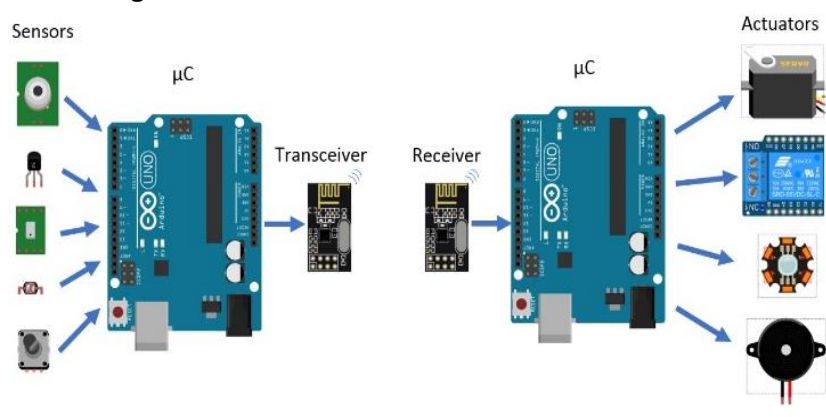

Figure 1. Concept of local wireless control system with multiple sensors and actuators

\section{NRF24L01 RF MODULE}

The device works as transceiver module, so each module can send and receive data. The transmission is half-duplex, they can either send or receive data at a time. These modules operate at a frequency of $2.4 \mathrm{GHz}$ (Industrial Science Medical -ISM band) with a transfer rate from $250 \mathrm{kbit} / \mathrm{s}$ to $2 \mathrm{Mbit} / \mathrm{s}$, which is legal in many countries and can be used in industrial and medical applications. With suitable antennas, they can transmit and receive information up to 100 meters between them (Fig. 2) [nRF24L01 2020a].

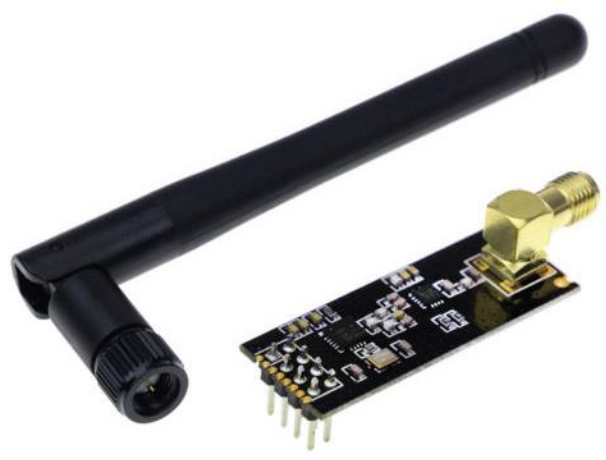

Figure 2. nRF24L01 module

The modules work with a power supply of 1.9 to $3.6 \mathrm{~V}$ and have a consumption of $12 \mathrm{~mA}$ during normal operation. This makes the devices very battery friendly for the remote systems. The module communicates with the controller via the SPI protocol. Most of the module pins are $5 \mathrm{~V}$ tolerant and can be easily interfaced with the Arduino like microcontrollers. Each module 
can communicate through 6 "Pipelines", which means that each module can communicate with 6 other modules to transmit or receive data. This makes the module suitable to create star and mesh topology networks of loT systems (Fig. 3).

The module must be configured within the control software of the connected microcontroller. There are available configurations defining the transfer speed, communication channel, power amplification, message size.

The pinout of the used communication module is described in the table below (Tab. 1). The table also shows the position of each pin.

Table 1. nRF24 module pins

\begin{tabular}{|l|l|l|l|}
\hline Function & Pin & Pin & Function \\
\hline GND & $\mathbf{1}$ & 2 & VCC \\
\hline CE & 3 & 4 & CSN \\
\hline SCK & 5 & 6 & MOSI \\
\hline MISO & 7 & 8 & IRQ \\
\hline
\end{tabular}

- $\quad$ GND is the ground pin for OV and is usually marked as a reference for identifying the other pins.

- $\quad$ VCC is the power pin.

- $\quad$ CE (Chip Enable) is an active-HIGH pin, when selected the module transmits or receives, depending on the mode.

- $\quad \operatorname{CSN}$ (Chip Select Not) is an active-LOW pin. When this pin is low the module starts to listen on its SPI port for data and processes it accordingly.

- SCK (Serial Clock) accepts clock pulses provided by the SPI bus Master.

- MOSI (Master Out Slave In) is the SPI input to the module.

- MISO (Master In Slave Out) is the SPI output from the module.

- $\quad \mathrm{IRQ}$ is an interrupt pin that can alert the master when new data is available to processes [nRF24L01 2020b].

In our case, the address was chosen 0 , while the communication channel is 115 out of the available 125 .

The channel sets the frequency according to the following formula:

$$
\begin{aligned}
& \text { Freq }_{\text {Selected }}=2400+C h_{\text {Selected }} \\
& \text { Freq }_{115}=2400+C h_{115}=2515 \mathrm{MHz}
\end{aligned}
$$

The speed can variate from $250 \mathrm{~kb} / \mathrm{s}$ to $2 \mathrm{Mb} / \mathrm{s}$. The power levels for the radio amplifier are adjustable to MIN, HIGH or MAX. For the maximum range, the MAX is recommended but this creates an increased current consumption, so in the case of batterypowered systems this must be considered while calculating the battery life.

As the module includes a power amplifier (PA) and low-noise amplifier (LNA) transmit, receive switching circuitry there are significant transmission ranges that the device can achieve.

The PA merely boosts the power of the signal being transmitted. The LNA takes the extremely weak uncertain signal of microvolts (under $-100 \mathrm{dBm}$ ) and amplifies it to a more useful level ( 0.5 to 1 Volt).

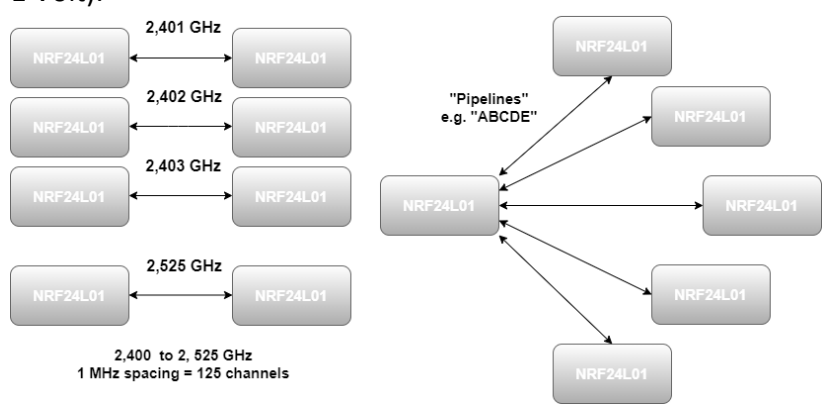

Figure 3. nRF24 channeling principle

\section{ARDUINO UNO R3}

Arduino Uno is a microprocessor board based on ATmega328P. It has 14 digital I/O pins (6 of which can be used as PWM outputs), 6 analog inputs, USB connector, power connector, ICSP header and reset button. It can be easily connected to a computer using a USB cable powered by an AC adapter or a battery [Arduino 2020].

The microcontroller uses $5 \mathrm{~V}$ operating voltage, for inputs and outputs too. The maximum current is $20 \mathrm{~mA}$ for $5 \mathrm{~V}$ and $50 \mathrm{~mA}$ for 3.3V signals. The communication can be carried out by UART, I2C or SPI protocols. For further option an outer communication module is needed.

\section{MICROSERVO}

For testing the proposed system, a microservo is used as an actuator. We chose the MG90S microservo. This electrical actuator is suitable for controlling the position of small objects and is used in remote control applications such RC models. The movement of the servo is limited between $0^{\circ}$ and $180^{\circ}$, or $\pm 90^{\circ}$ in each direction. The technical parameters of the MG90S are described in the table below (Tab. 2) [MG90S 2020].

Table 2. Technical parameters MG90S

\begin{tabular}{|l|}
\hline Parameter \\
\hline Weight \\
\hline Operating voltage \\
\hline Current \\
\hline Torque (4.8 V) \\
\hline Torque (6 V) \\
\hline Operating speed (4.8 V) \\
\hline Operating speed $(6 \mathrm{~V})$ \\
\hline Dead band width \\
\hline
\end{tabular}

\begin{tabular}{l} 
Value \\
$13.4 \mathrm{~g}$ \\
$4.8-6 \mathrm{~V}$ \\
$10-250 \mathrm{~mA}$ (stall $700 \mathrm{~mA}$ ) \\
$0.18 \mathrm{Nm}$ \\
$0.22 \mathrm{Nm}$ \\
$0.1 \mathrm{~s} / 60^{\circ}$ \\
\hline $0.08 \mathrm{~s} / 60^{\circ}$ \\
\hline $5 \mathrm{~s}$
\end{tabular}

\section{SOFTWARE}

Since we're implementing the Arduino microcontrollers, as programming environment the Arduino IDE is used (Fig. 4). It's a Java application, used to program different microcontrollers such Arduino and its clones. The main software includes a text programming code editor, with integrated code compiler a tool for code uploading and monitoring functionalities [Arduino 
2020]. The programmed control software includes the following functional parts:

- Library call

- Variable declaration

- $\quad$ /OO device configuration

- Communication configuration

- Main control loop

@ sketch_apr09a | Arduino 1.8.12 (Windows Store 1.8.33.0) $\quad-\quad \square \quad \times$ Súbor Editovat' Projekt Nástroje Pomoc

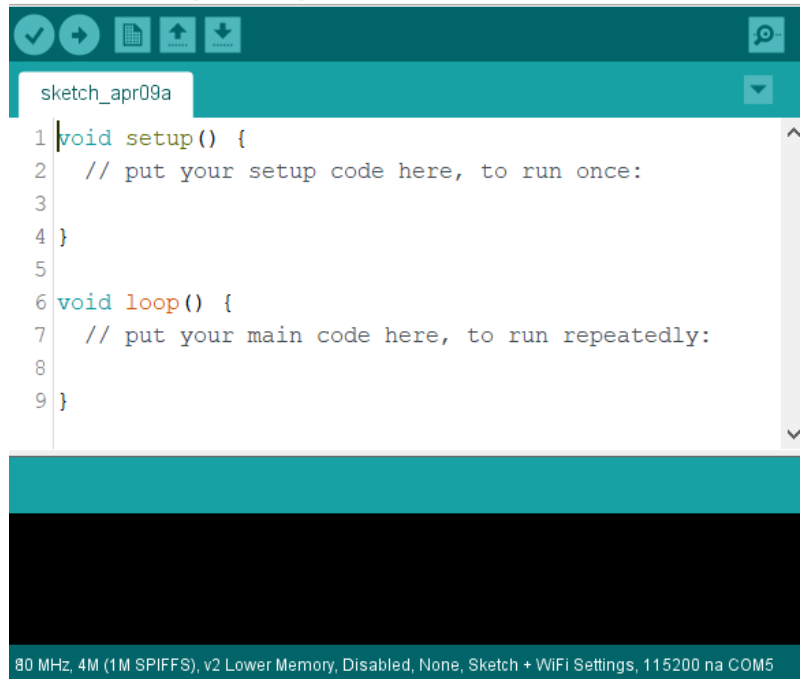

Figure 4. Arduino IDE

Control algorithms (Fig. 5) were used to describe the control software. The left algorithm shows the controller side with the potentiometer, while the right side describes the controlled actuating side with the servomotor.
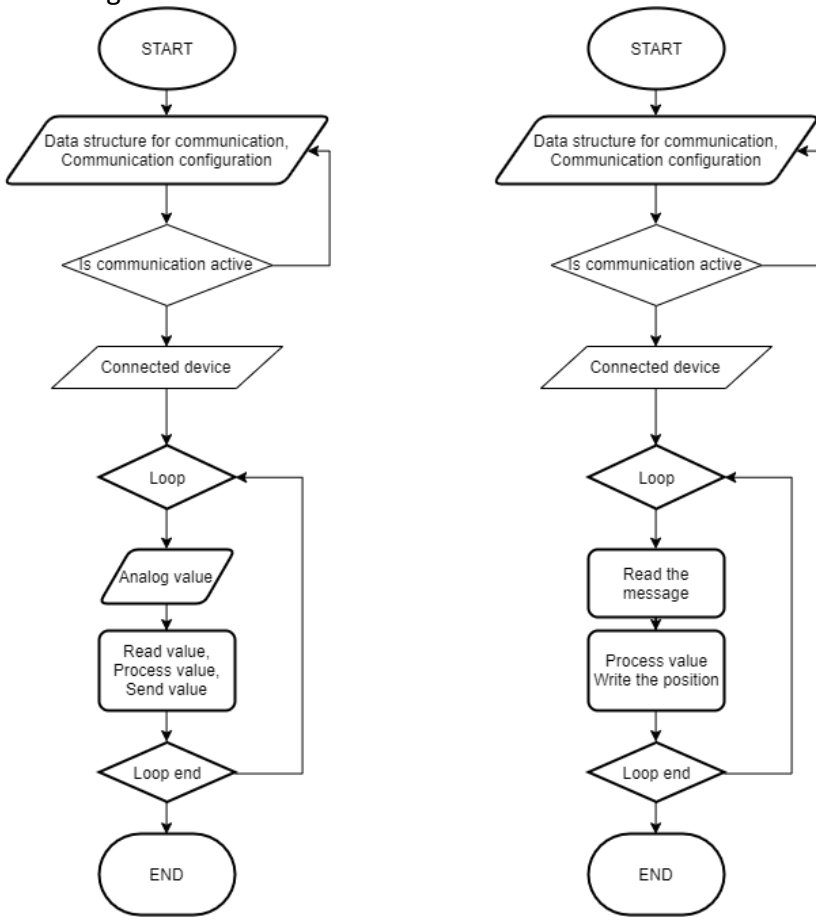

Figure 5. Control diagram
As mentioned before variable declaration and library calls are placed at the beginning of the code. These steps integrate the necessary functionalities to work with the connected input/output devices and with the communication modules. The variables define the memory space where the values of the potentiometer, control values, communication variables are stored. As next step the communication is configured. The control loop follows which is repeated cyclically.

\section{PROPOSED SYSTEM}

The tests were carried out in laboratory environment. The Figure 6 below describes the real connection of each pin on both sides of the system. As the picture shows the main control units are Arduino Rev3. During the experiments the USB power supply cables were used, but this can be easily replaced by a battery unit. Also, the USB connection allows the monitoring of different values such as the control angle and fast software uploading.
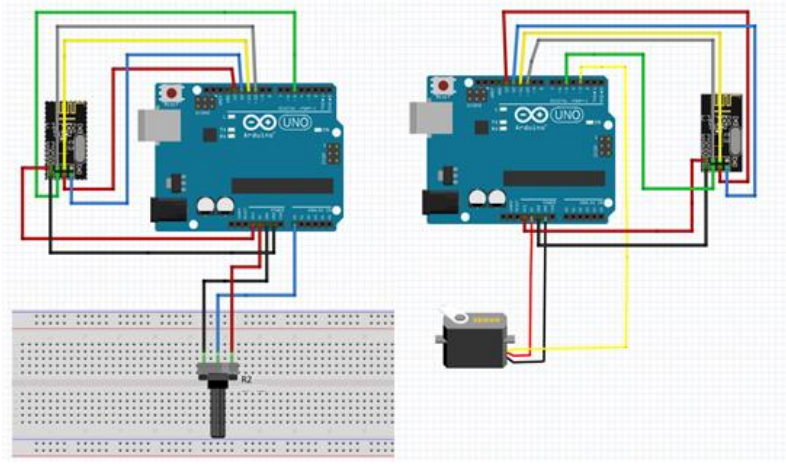

Figure 6 . Wiring of the system

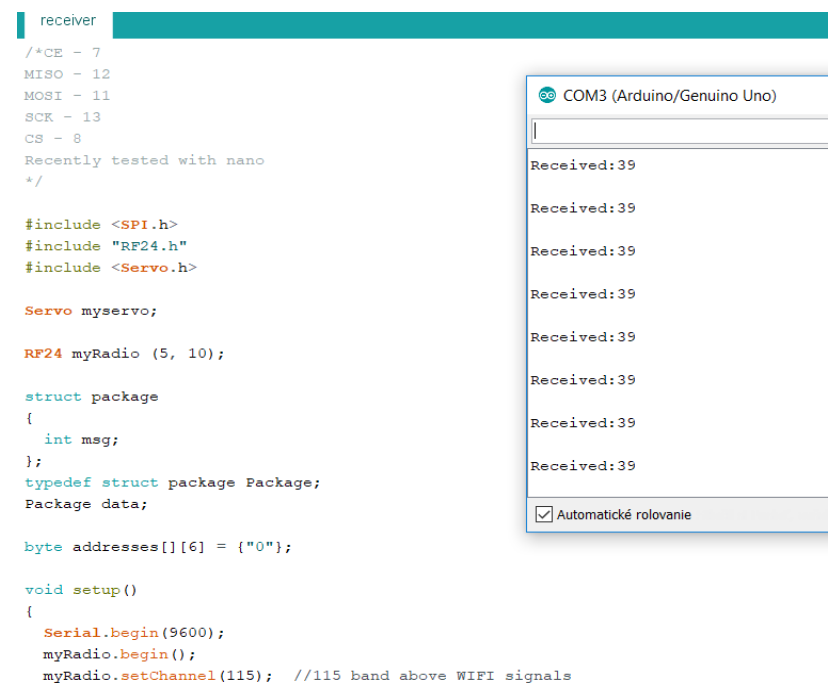

Figure 7. Control program and Serial monitor during tests

The communication between the PC, Arduino and the other Arduino is configured as follows:

- Baud rate of data transmission between PC and Arduinos is set to $9600 \mathrm{bit} / \mathrm{s}$.

- The RF communication between Arduinos is proceeded on channel No. 115.

- The speed of wireless transfer was $250 \mathrm{Kbit} / \mathrm{s}$. 
- The power amplifier was chosen to be LOW because of the short distance between the communicating parts.

The final wiring of the connected parts is shown on Fig. 6 . The left assembly is the sender, controlling side, and the right assembly is the receiver with the servomotor.

A wireless connection was created for testing. To evaluate connection, we compared the data sent and received. The testing was successful. Because of the communication protocol definition, while the transmitting parts are in range there is no communication error. The Figure 7 below includes detail view of declared variables, used libraries, a help for the wiring. The figure includes also a detail on the received data in the Serial monitor window.

\section{CONCLUSIONS}

In this paper a remote control system was proposed. The proposed system is not directly suitable for a real-life solution but can be used as a good basis for such system. To fulfill a reallife task requirement its necessary to replace the actuator with a more powerful servo motor, and the power consumption has to be analyzed. In the case model the system is aimed to test the communication and control of the actuator by using a wireless connection. The nRF communication protocol is a lightweight transfer technology working in the range of standardized ISM band. With its characteristics it's well suitable for simple home automation systems, where one or more physical tasks are replaced with electrical devices. As an actuator an RC servomotor is implemented on the receiver side. The position of the servomotor is determined by the received messages from the sender side. The input value of the system is created with a potentiometer and analog voltage to digital data conversion. The carried-out experiment showed that to automate tasks as lighting and dimmer control a remotely controlled actuator is well suitable solution. This type of automated system can help elderly people and people with disabilities to make their everyday life easier or comfortable or more independent. By combining batteries with these systems, we can create simple powerful micro automated systems. Compared to commercially available systems the proposed solution offer advantages as reconfigurability with different peripheral devices, reusability in various tasks and provides good basis of knowledge in the education of students of automation and mechatronics.

\section{ACKNOWLEDGMENTS}

This work has been supported by the Slovak Grant VEGA 1/0330/19 Research and design of algorithms and systems for fusion of disparate data in multisensor architectures (Výskum a návrh algoritmov a systémov pre fúziu rôznorodých dát $v$ multisenzorových architektúrach) and H2020: Manufacturing Industry Digital Innovation Hubs (MIDIH), reference No. 767498.

\section{REFERENCES}

[Arduino 2020] Arduino UNO REV 3 Datasheet (2020), Available from: <https://store.arduino.cc/arduino-unorev3https://store.arduino.cc/arduino-uno->
[Galajdova 2019] Galajdova, A., Simsik, D., Dolina, Z. Testing of E-services for Seniors and People with Disabilities within Einclusion Project MonAMI. International Journal of Rehabilitation Research, 2009, Vol. 32, pp. 75-76. ISSN 03425282.

[Kar 2017] Kar, U.N., Sanyan, D.K. An overview of device-todevice communication in cellular networks. ICT express. Available

from: <https://www.sciencedirect.com/science/article/pii/S24059595 17301467>

[Ketshabetswe 2019] Ketshabetswe, L.K. et al. Communication protocols for wireless sensor networks: A survey and comparison. Heliyon, 2019 Available from: <https://www.sciencedirect.com/science/article/pii/S24058440 18340192?via\%3Dihub>

[Krenicky 2011] Krenicky, T. Implementation of Virtual Instrumentation for Machinery Monitoring. In: Scientific Papers: Operation and Diagnostics of Machines and Production Systems Operational States: Vol. 4, RAM-Verlag, Lüdenscheid, 2011, pp. 5-8. ISBN 978-3-942303-10-1

[MG90S 2020] MG90S Datasheet (2020), Available from: $<$ https://protosupplies.com/product/servo-motor-micromg90s/>

[nRF24L01 2020a] nRF24L01 Datasheet (2020), Available from: <https://www.sparkfun.com/datasheets/Components/nRF24L0 1_prelim_prod_spec_1_2.pdf >

[nRF24L01 2020b] nRF24L01 Datasheet (2020), Available from: <https://www.electronics-lab.com/project/communicationbetween-two-arduinos-using-nrf24|01/>

[Seminsky 2015] Šeminský, J. Near future manufacturing systems - present and future. Interdisciplinarity in Theory and Practice, 2015, No. 8, pp. 282-284. ISSN 2344-2409

[Simsík 2016] Šimšík, D., Galajdová, A., Šeminský, J., Rákay, R., Višňovský, M. Innovation of the study program automation and control of machines and processes in response to the requirements of industrial practice (Inovácia študijného programu automatizácia a riadenie strojov a procesov $\mathrm{v}$ reakcii na požiadavky priemyselnej praxe). ARaP, 2016, Prague: MM publishing, pp. 79-82. ISBN 978-80-906310-1-4.

\section{CONTACTS}

Assoc. Prof. MSc. Alena Galajdova, PhD.

Technical University of Košice, Faculty of Mechanical Engineering,

Department of Automation and Human Machine Interactions, Park Komenského 8, 04200 Košice, Slovakia alena.galajdova@tuke.sk

\section{MSc. Robert Rakay, PhD.}

Technical University of Košice, Faculty of Mechanical Engineering,

Department of Automation and Human Machine Interactions, Park Komenského 8, 04200 Košice, Slovakia robert.rakay@tuke.sk 